\title{
Modelling the recovery of acid-sensitive Finnish headwater lakes under present emission reduction agreements
}

\author{
M. Posch ${ }^{1}$, M. Forsius², M. Johansson², J. Vuorenmaa ${ }^{2}$ and J. Kämäri² \\ ${ }^{1}$ Coordination Center for Effects/RIVM, PO Box 1, NL-3720 BA Bilthoven, The Netherlands \\ ${ }^{2}$ Finnish Environment Institute (SYKE), PO Box 140, FIN-00251 Helsinki, Finland
}

Email for corresponding author: max.posch@rivm.nl

\begin{abstract}
Over the past two decades, substantial reductions in the deposition of acidifying substances (primarily sulphur) have occurred in most parts of Europe and, following recent agreements, this trend is likely to continue. The question arises as to how have sensitive ecosystems reacted, and will react in the future, to these reduced inputs of acidity? In this paper, the SMART dynamic acidification model predicts the possible recovery of 36 acid-sensitive Finnish headwater lakes, for which both catchment soil and water quality measurements were available. The model was calibrated to measurements by adjusting poorly known parameters; it was then used to simulate soil and water chemistry until 2030 under the 'current legislation scenario' resulting from implementing current European emission reduction agreements. Whereas most of the catchment soils show very little change in base saturation, the positive trends in lake ANC and the negative trends in lake sulphate concentrations, observed over the past decade, continue into the future, albeit at a slower pace. The model predicts that, during 2010-30, all lakes will have reached a positive $\mathrm{ANC}$, a pre-requisite for the recovery of fish populations.
\end{abstract}

Keywords: acidification, lake, catchment, recovery, SMART model, Finland

\section{Introduction}

During the last decades, large efforts have been made to reduce European emissions of air pollutants. Recent key international agreements have been the 1999 Gothenburg Protocol of the Convention on Long-range Transboundary Air Pollution (LRTAP) of the United Nations Economic Commission for Europe (UNECE) and the Directive 2001/ 81/EC of the European Parliament and of the Council of 23 October 2001 on national emission ceilings (NEC) for certain atmospheric pollutants. Between 1990 and 1998, European emissions of $\mathrm{SO}_{2}, \mathrm{NO}_{\mathrm{x}}$ and $\mathrm{NH}_{3}$ have declined by 41, 21 and 14\%, respectively (Vestreng and Støren, 2000). Compared to 1990 measurements, implementation of the Gothenburg Protocol would cut Europe's sulphur emissions by at least $63 \%, \mathrm{NO}_{\mathrm{x}}$ emissions by $41 \%, \mathrm{NH}_{3}$ emissions by $17 \%$ and VOC emissions by $40 \%$ by the year 2010 . Large monitoring and assessment systems for analysing the effects of these emission reduction efforts have been set up both nationally and internationally. The International Cooperative Programmes (ICPs) under the LRTAP Convention have undertaken effects-monitoring of different ecosystems and established large databases on critical thresholds for air pollutants in Europe (Bull et al., 2001). Recently, to gain insight into the temporal aspects ('recovery times') of ecosystems, dynamic modelling has become an important part of the effects-oriented work under the LRTAP Convention (Posch et al., 2003).

Surface waters have been shown to be susceptible indicators of air pollution impacts. Several large international studies have recently assessed the recovery of headwater lakes and streams from acidification. Stoddard et al. (1999) observed regional recovery in surface water buffering capacity in all regions studied in Europe, but in only one region (of five) in North America. The lack of recovery was attributed to strong declines in base cation concentrations exceeding the decreases in sulphate. Evans 
et al. (2001) analysed data from 56 long-term monitoring sites in eight European countries. The majority of sites (38 out of 56) showed significant decreasing trends in pollutionderived sulphate. Increases in acid neutralising capacity (ANC) were significant at 26 of 56 sites. Increases in ANC were accompanied by increases in $\mathrm{pH}$ and reductions in aluminium, although fewer trends were significant (pH: 19 of 56, aluminium: 13 of 53).

Also in Finland, acidification recovery in lakes has been studied intensively. The chemistry of 163 acid sensitive lakes was measured during the autumn overturn in 1987 and monitored continuously since 1990. Mannio (2001) detected statistically significant reductions in sulphate concentrations in $60-80 \%$ of the lakes, depending on the region. Forsius et al. (2003) estimated that some 1400 (27\%) of Finnish headwater lakes of size 4-100 ha show an increase in Gran alkalinity (recovery). The number of lakes (1400) is an estimate, derived by combing monitoring and lake survey data. The median slope of the trend for Gran alkalinity ranged between 0.98 and $2.1 \mu \mathrm{eq} \mathrm{L} \mathrm{L}^{-1} \mathrm{yr}^{-1}$. First signs of a recovery of perch (Perca fluviatilis) populations have also been recorded (Rask et al., 1995, 2001).

Long-term empirical data, such as the studies cited above, give valuable information about recorded trends in various ecosystems. Dynamic process-oriented models are needed to predict the gradual chemical response of a receptor to changing depositions by including the various buffer and adsorption/desorption mechanisms. The time development of acidification is important e.g. for determining the timing of necessary measures for emission control and for assessing the dynamic response of possible critical load exceedances. Several dynamic models, such as MAGIC (Cosby et al., 1985, 2001), SAFE (Warfvinge et al., 1993) and SMART (De Vries et al., 1989), have been developed and used extensively on both site-specific and regional scales to predict changes in soil and surface water chemistry (e.g. De Vries et al., 1994; Alveteg et al., 1995; Jenkins and Cullen, 2001).

The main aims of this paper are:

- to calibrate the dynamic SMART acidification model to a subset of the Finnish acidification monitoring lakes against the available monitoring and survey data and, using the calibrated SMART model;

- to estimate the potential for continued recovery of the monitoring lakes for best estimates of future deposition patterns for $\mathrm{S}$ and $\mathrm{N}$ derived for each lake on the basis of agreed/anticipated deposition reduction measures.

\section{Materials and methods}

DATA

The lake data set used in the study is a subset of the Finnish acidification monitoring lake network (RMLA) (Mannio, 2001; Forsius et al., 2003). The RMLA lakes $(\mathrm{n}=163)$ are mostly small acid-sensitive (median area $=10$ ha) head water or seepage lakes and their catchments are forested and relatively undisturbed. Originally, these lakes were chosen subjectively by expert judgement for use in national acidification studies. Median $\mathrm{pH}$ is 5.8 , total phosphorus $10 \mathrm{mg} \mathrm{L}^{-1}$ and base cation and sulphate concentrations are 137 and $63 \mu \mathrm{eq} \mathrm{L}^{-1}$, respectively. In a statistically-based survey of all Finnish lakes (Mannio et al., 2000), the corresponding values were $6.6(\mathrm{pH}), 13$ (total phosphorus), 240 (base cations) and 58 (sulphate). The 36 lakes chosen in the present study have water chemistry characteristics similar to those in the RMLA set (Table 1) but the lake size in the subset is, on average, larger than in the RMLA lake population (median lake size $21 \mathrm{ha}$ ). The lakes were sampled in 1987 and annually since 1990. A water sample is taken either from the middle of the lake (1 m depth) or at the outlet during the autumn thermal overturn. Runoff data were not available for individual years, so long-term averages were obtained from a digitised runoff map for 1961-1975 (Leppäjärvi, 1987). Selection of the lakes for this study depended on the availability of soil chemistry data, since these are key inputs to the SMART model. The locations of those 36 lakes are in Fig. 1.

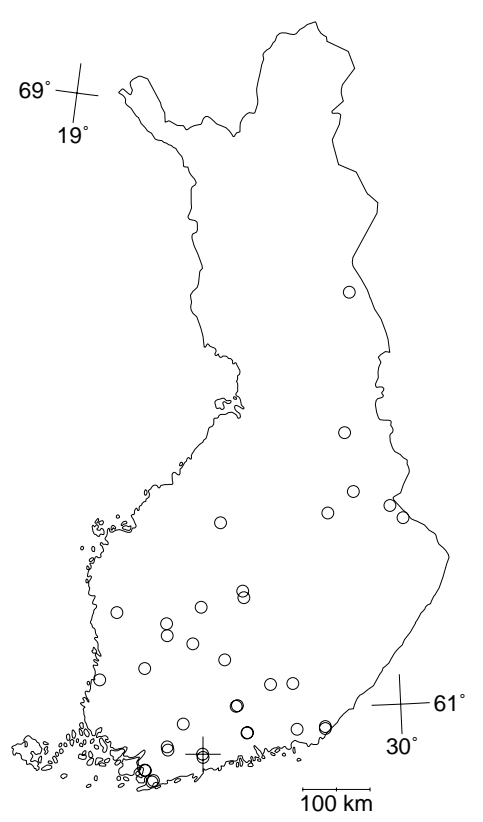

Fig. 1. Location of the 36 catchments in Finland used in this study. The cross near the southern coast indicates Lake Saarenmusta near Helsinki. 
Table 1. Statistical characteristics of key lake chemistry and catchment variables of the 36 lakes used in this study $(\mathrm{BC}=$ base cations; the $\operatorname{star}(*)$ denotes non-marine fraction, based on a Cl-correction).

\begin{tabular}{|c|c|c|c|c|c|c|c|c|c|c|}
\hline & $\min$. & $10 \%$ & $25 \%$ & median & mean & $75 \%$ & $90 \%$ & $\max$ & std.dev. & $C V \%$ \\
\hline $\mathrm{pH}$ & 4.65 & 5.03 & 5.27 & 5.92 & 5.81 & 6.23 & 6.47 & 6.77 & 0.56 & 9.6 \\
\hline $\mathrm{ANC}\left(\mu \mathrm{eqL} \mathrm{L}^{-1}\right)$ & -14.4 & -4.2 & 7.8 & 52.2 & 57.9 & 98.7 & 143.3 & 191.3 & 55.7 & 96 \\
\hline $\mathrm{BC}\left(\mu \mathrm{eqL} \mathrm{L}^{-1}\right)$ & 24.3 & 43.7 & 100.8 & 169.9 & 175.1 & 237.5 & 298.2 & 374.4 & 93.2 & 53 \\
\hline $\mathrm{BC}^{*}\left(\mu \mathrm{eqL} \mathrm{L}^{-1}\right)$ & 13.9 & 33.8 & 74.2 & 133 & 135.9 & 187.9 & 242 & 289.8 & 75.2 & 55 \\
\hline $\mathrm{Ca}+\mathrm{Mg}\left(\mu \mathrm{eqL}^{-1}\right)$ & 13.5 & 24.9 & 58.8 & 106.6 & 111.9 & 156.8 & 196.5 & 258.5 & 63.5 & 57 \\
\hline $\mathrm{Na}+\mathrm{K}\left(\mu \mathrm{eqL} \mathrm{L}^{-1}\right)$ & 10.8 & 18.2 & 42.9 & 59.8 & 63.2 & 86.2 & 99.4 & 134.2 & 31.7 & 50 \\
\hline $\mathrm{SO}_{4}\left(\mu \mathrm{eqL} \mathrm{L}^{-1}\right)$ & 25 & 31.9 & 49.6 & 88.2 & 81 & 107.4 & 125 & 142.3 & 34.8 & 43 \\
\hline $\mathrm{SO}_{4} *\left(\mu \mathrm{eqL} \mathrm{L}^{-1}\right)$ & 23.8 & 30.9 & 47.4 & 81.9 & 77.3 & 103 & 119.7 & 138.6 & 33.2 & 43 \\
\hline $\mathrm{Cl}\left(\mu \mathrm{eqL} \mathrm{L}^{-1}\right)$ & 7.5 & 9.4 & 17.6 & 36.2 & 35.3 & 44 & 70.5 & 95.9 & 21.8 & 62 \\
\hline $\mathrm{NO}_{3}-\mathrm{N}\left(\mu \mathrm{eqL} \mathrm{L}^{-1}\right)$ & 0.09 & 0.16 & 0.25 & 0.76 & 0.91 & 1.4 & 1.8 & 3.8 & 0.8 & 88 \\
\hline $\mathrm{NH}_{4}-\mathrm{N}\left(\mu \mathrm{eqL} \mathrm{L}^{-1}\right)$ & 0.13 & 0.27 & 0.4 & 0.94 & 1.5 & 1.4 & 4 & 6.9 & 1.6 & 112 \\
\hline tot $\mathrm{P}\left(\mu \mathrm{gL} \mathrm{L}^{-1}\right)$ & 4 & 5 & 5 & 7 & 8 & 10 & 16 & 20 & 4.3 & 51 \\
\hline TOC $\left(\mathrm{mgL}^{-1}\right)$ & 0.4 & 1.6 & 2.4 & 4.3 & 4.9 & 7.5 & 9.6 & 11 & 2.9 & 58 \\
\hline Conductivity $\left(\mathrm{mSm}^{-1}\right)$ & 0.8 & 0.9 & 1.4 & 2.3 & 2.2 & 2.8 & 3.4 & 4.2 & 0.9 & 42 \\
\hline Lake area (ha) & 3 & 4 & 8 & 21 & 32 & 43 & 92 & 162 & 35.1 & 110 \\
\hline Catchment area (ha) & 16 & 24 & 41 & 89 & 169 & 251 & 436 & 800 & 176.9 & 105 \\
\hline Peatland area (\%) & 0 & 3 & 4 & 10 & 12 & 15 & 34 & 41 & 10.5 & 88 \\
\hline Exposed bedrock (\%) & 0 & 0 & 0 & 1 & 7 & 9 & 29 & 46 & 13 & 177 \\
\hline
\end{tabular}

The soil chemistry data were collected during the Finnish Acidification Research Programme HAPRO (Nuotio et al., 1985, 1990). The soil and bedrock of the catchments were determined with the aid of map interpretation and field studies. Soil samples were taken from (up to) six major soil classes within each catchment. Samples from the mineral soil were taken from the A0, A1-A2 and B podzol horizons as well as from fixed depths of 50-60 cm and 90-100 cm (if possible). The peat samples were taken from fixed depths of 0-10, 50-60 and 90-100 cm. The representativeness of single samples in relation to other samples was tested by repeated sampling. Chemical analyses were made on the $<2 \mathrm{~mm}$ fraction using ammonium-acetate extraction at $\mathrm{pH}=4.65$ to obtain the potentially exchangeable $\left(C E C_{p}\right)$ and readily soluble $\left(B C_{p}\right)$ base cations. The analytical methods are detailed in Nuotio et al. $(1985,1990)$.

To apply the SMART model, a single base saturation value, $E_{B C}=E_{C a}+E_{M g}$, had to be computed for each catchment. This was done by depth-, density- and areaweighted averaging of the CEC and base saturation as follows:

$E_{B C}=\sum_{j=1}^{n} A_{j} \sum_{i=1}^{m_{j}} z_{i, j} \rho_{i, j} C E C_{i, j} E_{B C, i, j} / \sum_{j=1}^{n} A_{j} \sum_{i=1}^{m_{j}} z_{i, j} \rho_{i, j} C E C_{i, j}$

where $z_{i, j}, \rho_{i, j^{\prime}} C E C_{i, j}$ and $E_{B C, i, j}$ refer to the thickness, density, CEC and base saturation of layer $i\left(i=1, \ldots m_{j}\right)$ of soil class $j$ covering an area $A_{j}(j=1, \ldots, n)$. Data to a maximum depth of $60 \mathrm{~cm}$ were used to compute the catchment average. Bulk density was not measured: values of $0.1 \mathrm{~g} \mathrm{~cm}^{-3}$ were assumed for the organic layer and $1.3 \mathrm{~g} \mathrm{~cm}^{-3}$ for the mineral soil.

The long-term average base cation weathering in Finland (Johansson and Tarvainen, 1997) was estimated by applying a method used in Swedish field studies (Olsson and Melkerud, 1991; Olsson et al., 1993); this is considered applicable for Finland, because the geological history after the last deglaciation is similar to that of Sweden. By reference to the resistant zirconium mineral content, the method correlates the historic loss of material in topsoil with temperature and the initial content of the element still prevailing in the bottom soil. Data needed are the effective temperature sum (ETS) above a threshold of $5^{\circ} \mathrm{C}$ and the total element content of $\mathrm{Ca}, \mathrm{Mg}, \mathrm{K}$ and $\mathrm{Na}$ in the unchanged bottom soil horizon. Total analysis data on the coarse $<2.0 \mathrm{~mm}$ fraction of till required by the method were obtained directly for 618 plots of the Geological Survey of Finland and calculated for an additional 439 plots using the average element content specific coarse to fine $(0.063 \mathrm{~mm})$ fraction ratios available from 618 plots. The weathering rate for each base cation was estimated separately in each plot and the three nearest plots were used to derive catchmentspecific values. For an uncertainty analysis see Johansson and Janssen (1994) and for a comparison with other methods see Starr et al. (1998).

The long-term average annual net uptake of base cations 
and nitrogen by forests was calculated from the average annual volume growth and the nutrient concentrations in the removed biomass (stem over bark). The average annual forest growth in Finland was estimated from the national forest inventory for 1970-76 (Kuusela, 1977). The total forest area and total annual volume growth for three tree species (deciduous, spruce, pine) were given separately for 21 forest management districts with their average ETS values. These data were used to fit a logistic function, which allows estimating the average annual growth for each tree species at any location in Finland as a function of the local ETS. Biomass densities of each tree species (Mälkönen, 1975; Rosén, 1982) were used to convert average annual volume growth to mass increments. Finally, the annual average nutrient uptake was calculated using data on nutrient contents in biomass based on field measurements (Mälkönen 1975; Olsson et al., 1993; Rosén, 1982).

\section{DEPOSITION HISTORY AND SCENARIOS}

Temporal patterns in the deposition of sulphur and nitrogen compounds due to emissions in Europe were computed by multiplying country emissions for individual years with country-to-grid transfer matrices derived from 12 years (1985-96) of simulations of the EMEP Lagrangian longrange transport model; this gives results on a $150 \mathrm{~km} \times 150 \mathrm{~km}$ grid (EMEP/MSC-W, 1998). A detailed description can be found in Schöpp et al. (2003). The absolute levels of $\mathrm{S}$ and $\mathrm{N}$ depositions at each site were obtained by scaling those temporal patterns to the 1990 modelled deposition values consisting of the (non-Finnish) long-range transport (EMEP/MSC-W, 1998) and the domestic meso-scale dispersion due to local (Finnish) emissions (Johansson et al., 1990; Syri et al., 1998) with a spatial longitude-latitude resolution of $0.25^{\circ} \times 0.125^{\circ}$. The scenario used for the deposition of S and $\mathrm{N}$ after 2000 is the 'current legislation scenario' which assumes the implementation of the 1999 Gothenburg Protocol of the LRTAP Convention as well as of the NEC Directive (Schöpp et al., 2003). In Fig.2, the temporal development (19602030) of the depositions of sulphur, $\mathrm{NO}_{x}$ and $\mathrm{NH}_{3}$ at Lake Saarenmusta in southern Finland (Fig. 1) are displayed. Sulphur deposition has declined dramatically since 1980 and $\mathrm{NO}_{\mathrm{x}}$ deposition will be reduced to about half in 2010 from its peak in the eighties, whereas $\mathrm{NH}_{3}$ deposition is almost constant throughout the period. The scenario predicts that all three depositions will be about the same (in equivalent terms) after the year 2010. The deposition patterns are very similar at all sites, with declining absolute amounts further north.

The deposition of base cations $(\mathrm{Ca}, \mathrm{Mg}, \mathrm{K}$ and $\mathrm{Na})$ and

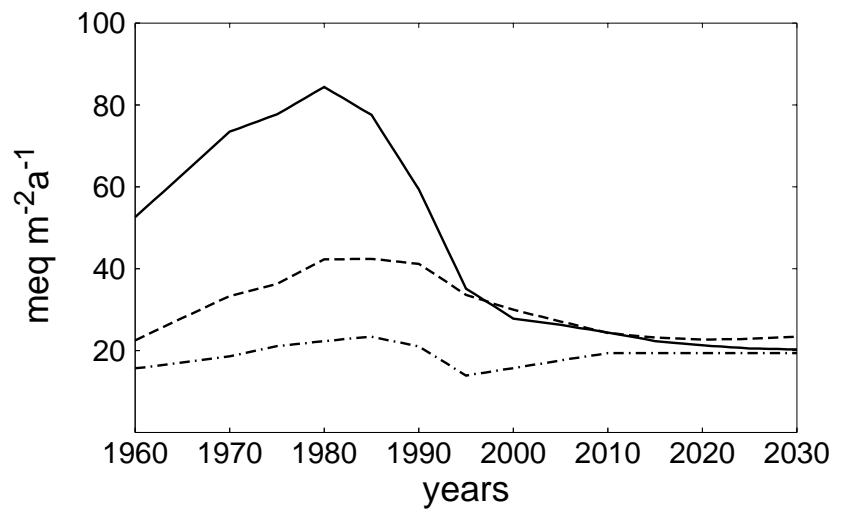

Fig. 2. Temporal development (1960-2030) of the deposition of sulphur (solid line), $\mathrm{NO}_{x}$ (dashed line) and $\mathrm{NH}_{3}$ (dashed-dotted line; all in meq $\mathrm{m}^{-2} \mathrm{a}^{-1}$ ) at Lake Saarenmusta in southern Finland.

chloride for each catchment was obtained by interpolating observations for the years 1993-95 of a nation-wide network of some 38 stations measuring monthly bulk deposition (Järvinen and Vänni, 1990). Base cation and chloride deposition were assumed constant throughout the modelling period.

\section{THE SMART MODEL}

The Soil Model for Acidification's Regional Trends (SMART) was used to simulate the acidification and recovery of the 36 Finnish lakes. SMART consists of a set of mass balance equations, describing the soil input-output relationships of the major ions including organic anions and a set of equations describing the rate-limited and equilibrium soil processes. The soil solution chemistry depends solely on the net input of elements from the atmosphere (deposition minus net uptake minus net immobilisation) and the geochemical interaction in the soil $\left(\mathrm{CO}_{2}\right.$ equilibria, weathering and cation exchange). Soil interactions are described by simple rate-limited (zero-order) reactions (e.g. uptake and weathering) or by equilibrium reactions (e.g. cation exchange). Cation exchange is modelled for $\mathrm{Al}, \mathrm{H}$ and the sum of divalent base cations $(\mathrm{Ca}+\mathrm{Mg})$, whereas the exchange of $\mathrm{K}$ and $\mathrm{Na}$ is neglected. Complete mixing of the element input within a single homogeneous soil compartment with a constant density is assumed, thus predicting the concentration of the soil water leaving this layer. The dissociation of organic acids is modelled both in the soil and in the lake with the empirical relationship of Oliver et al. (1983) using measured TOC concentrations and a charge density of $6 \mu \mathrm{eq} / \mathrm{mgC}$. The water flux percolating from this layer is assumed equal to the precipitation excess. The time step of the model is one year, i.e. seasonal variations are not considered. A detailed 
description of the SMART model can be found in De Vries et al. (1989) and Posch et al. (1993). While in the original SMART model, cation exchange was modelled with GainesThomas equations (as used in the MAGIC model), it is now alternatively possible to select the Gapon description of the exchange processes (as used in the SAFE model). The latter has been used in the present study.

The lake water chemistry is simulated using an add-on module for the SMART model which computes the concentrations of major ions in the lake water, using the ion fluxes from the catchment soils and direct atmospheric deposition as inputs. In-lake processes modelled are the retention of sulphate, nitrate and ammonium (according to Baker and Brezonik, 1988) as well as the precipitation of $\mathrm{Al}$ as $\mathrm{CO}_{2}$ degasses. A description of the lake module can be found in Kämäri et al. (1995).

\section{Model calibration}

The SMART model was calibrated to the 36 catchments in a sequential procedure. The model was calibrated separately for each lake against the average base saturation measured in 1984 in the catchment soils and the six-year (1990-95) average observed concentration of the major ions in the lake samples. (More recent observations have not been used in the calibration since it is planned to use them for model validation.) In the first place, the depositions of ions that are assumed to act conservatively were calibrated to match the observed concentration of these ions in the lake. These are chloride and the monovalent base cations $\mathrm{K}$ and $\mathrm{Na}$, which do not take part in the cation exchange reactions in the SMART model. If the average $\mathrm{K}$ or $\mathrm{Na}$ deposition were smaller than the respective observed concentration multiplied by the runoff, the weathering rates and, in the case of $\mathrm{K}$ also, the uptake of these ions was adjusted.

No adsorption of sulphate in the catchment soils was assumed but sulphate retention in the lake/sediment was modelled in SMART. To match sulphate deposition and modelled $\mathrm{SO}_{4}$ concentration, the mass-transfer coefficient for the in-lake retention was adjusted between values of zero and $1 \mathrm{~m} \mathrm{yr}^{-1}$, which covers the (few) observed values for lakes in North America and northern Europe (Baker and Brezonik, 1988). If this were not sufficient to match model output and observations, the $\mathrm{S}$ deposition level was adjusted. It was assumed that all $\mathrm{NH}_{3}$ deposition falling onto the terrestrial catchment was completely nitrified, i.e. only deposition directly onto the lake contributed to the ammonium runoff. For ammonium and nitrate, the mass transfer coefficients were allowed to vary between zero and $10 \mathrm{~m} \mathrm{yr}^{-1}$, values covering the range of observations by Dillon and Molot (1990) of (mostly) Canadian lakes. This

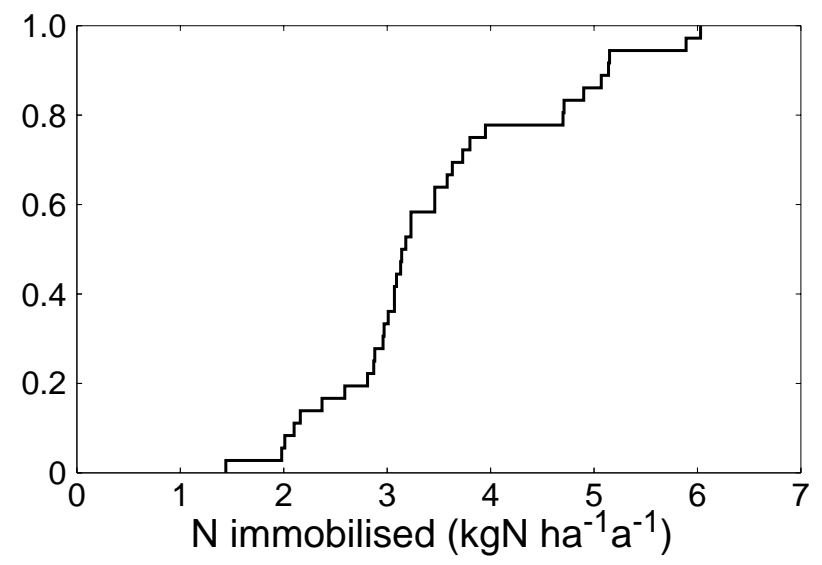

Fig. 3. Cumulative frequency distribution of the calibrated annual amount of $N$ immobilised in the 36 catchments of this study.

procedure was sufficient to match ammonium depositions and runoff concentrations. In the case of nitrate, if simulated concentrations were still too high (after allowing maximum retention in the lake), $\mathrm{N}$ immobilisation was adjusted until nitrate in the runoff matched averaged (1990-95) observations. In Fig. 3 the calibrated amounts of $\mathrm{NO}_{3}-\mathrm{N}$ immobilised in the 36 catchments are displayed, showing quite realistic values in all cases. These values were then used for the whole simulation period. Observed concentrations of $\mathrm{N}$ in Finnish lakes are quite low (Table 1), so that attention has to be focused on $\mathrm{S}$ as the main acidifying pollutant.

Finally, the parameters influencing the behaviour of divalent base cations $(\mathrm{Ca}+\mathrm{Mg})$ were calibrated. To this end, both the base saturation in 1960, i.e. the starting year of the simulations, and the exchange constants were adjusted so that the measured $\mathrm{Ca}+\mathrm{Mg}$ saturation in 1984 and the average (1990-95) observed lake water ANC were reproduced. Calibrating the 1960 base saturation differs from the calibration procedures in the SAFE and MAGIC model, where simulations start in pre-industrial times (usually around the 1850s) when it is assumed that base saturation is in equilibrium with inputs. However, pre-World War II depositions are highly uncertain or, in the case of base cations, virtually unknown; to by-pass these uncertainties, the 1960 base saturation was chosen to be calibrated. Unlike MAGIC, the SMART model does not include a module to allow calibrating several inter-dependent variables simultaneously. Thus, the calibrations in this study were limited to the variables mentioned above; certain variables, such as $\mathrm{pH}, \mathrm{Al}$ species or bicarbonate, were not calibrated (and consequently their future behaviour was not studied).

In Fig. 4 comparisons between calibrated and observed 

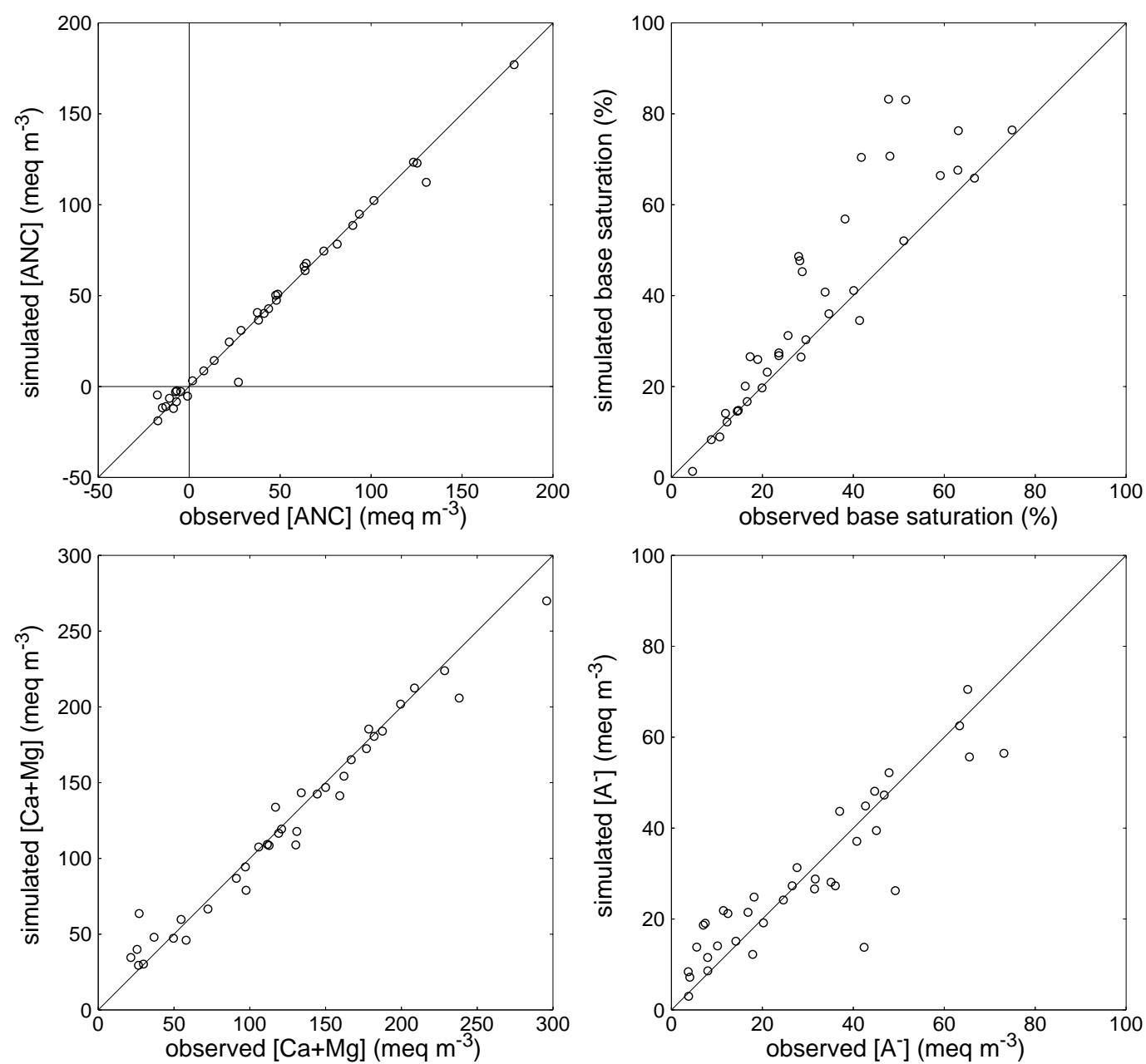

Fig. 4. Scatter diagrams showing the correlation between calibrated and observed values for lake ANC, Ca+Mg and organic anion concentrations (1990-95 averages) as well as catchment base saturation (1984 values) for the 36 lakes used in this study.

values of four major variables are shown as scatter diagrams for the 36 study lakes. In most cases, the calibrated model matches observed mean water chemistry and base saturation values rather well. Inconsistencies between observed and simulated values reflect the limitations of the calibration procedure and the (prescribed) uncertainties in the measured values. Although a comprehensive programme of measurements was carried out to estimate soil chemical variables at the sites studied (Nuotio et al., 1985, 1990), there are obviously large uncertainties involved in estimating representative depth and area weighted values for entire catchment areas.

\section{Results and discussion}

After calibration, the future behaviour of the 36 catchments was simulated until 2030 using the deposition scenario described above. As an example of the model calibration/ simulation, results for nine variables for Lake Saarenmusta $\left(60.34^{\circ} \mathrm{N}, 24.61^{\circ} \mathrm{E}\right)$ near Helsinki in southern Finland (Fig. 1) are shown in Fig. 5. The first graph shows the ANC input flux, calculated as the difference between the net input of base cations and strong acid anions. While the calibrated parameters reproduce, more or less, the trends during the years of observations, aluminium concentrations are simulated rather poorly. Aluminium concentrations in SMART are modelled with a gibbsite equilibrium and thus the total aluminium concentration measurements, which include Al complexed to organic matter, cannot be reproduced satisfactorily. This is one reason why aluminium has not been used as an indicator for recovery. Since only a long-term average water flux was used because of lack of data, the extremes in concentrations could not, in general, be reproduced in all cases; thus a calibration was accepted only if the mean of the observations was simulated reasonably well. 


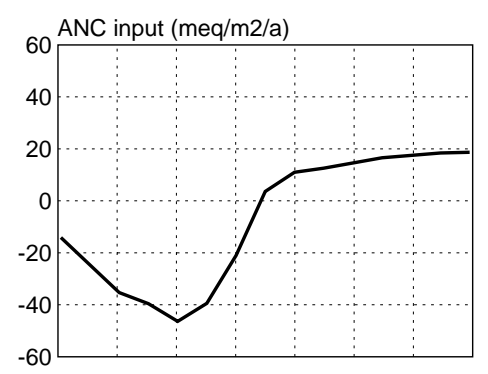

\section{6 - SAAREN MUSTA}
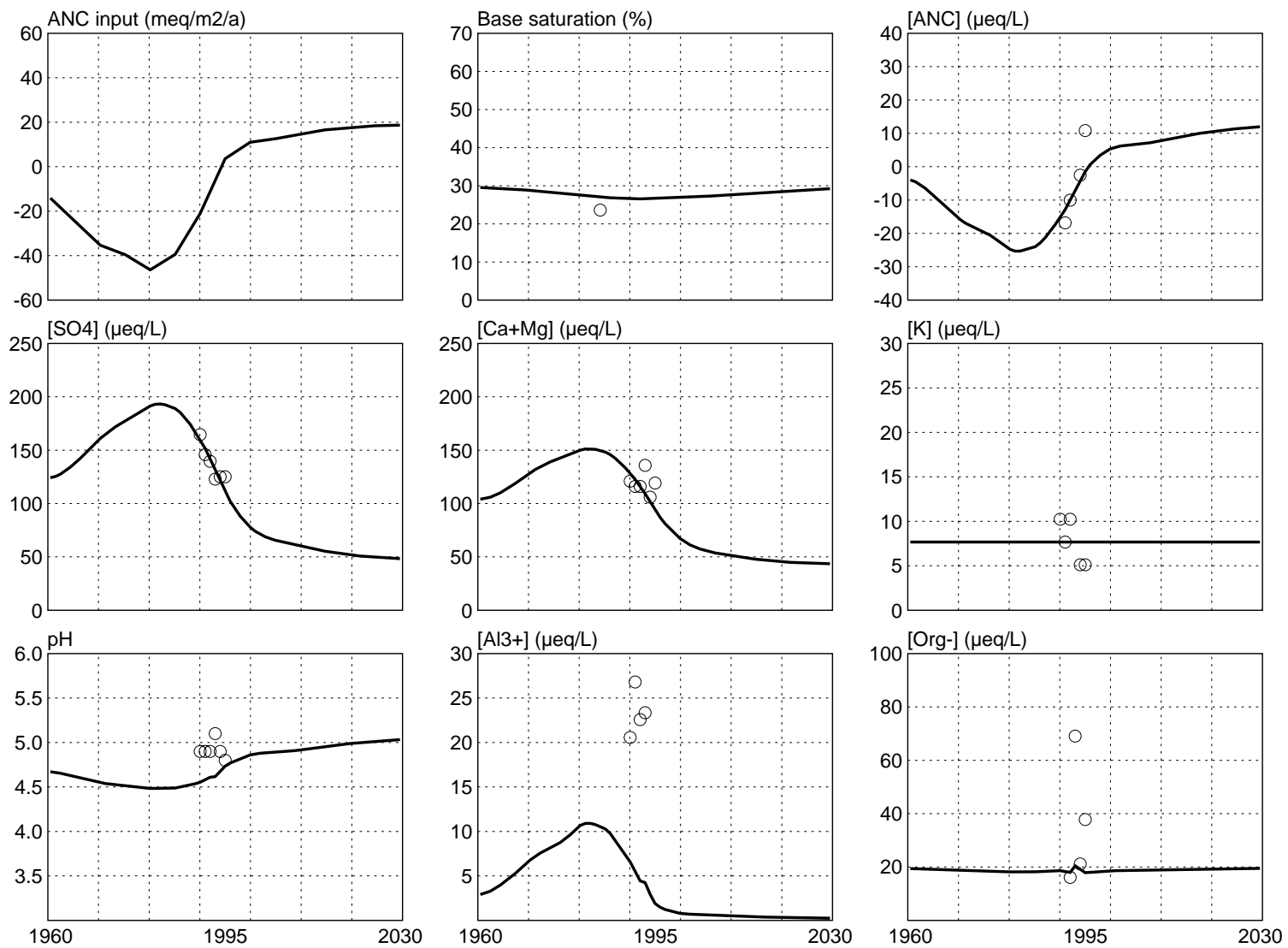

Fig. 5. Calibration/simulation results for Lake Saarenmusta (southern Finland) for nine (water and soil chemistry) variables.

Of the large number of model outputs potentially available, three key indicators have been chosen to demonstrate the regional model behaviour and future (until the year 2030) recovery patterns: $\mathrm{SO}_{4}$ concentration and ANC in lake water and base saturation in the catchment soils (Fig. 6). The reduction in $\mathrm{S}$ deposition is the main driving force for the acidification recovery process in Finland (Forsius et al., 2003). The median $\mathrm{NO}_{3}$ concentration of the modelled lakes is only $0.8 \mu \mathrm{eq} \mathrm{L} \mathrm{L}^{-1}$ (Table 1) and rather few statistically significant decreasing trends are found for $\mathrm{NO}_{3}$ for the RMLA lakes. Future changes in $\mathrm{N}$ emissions are, therefore, not expected to have any major impact on the acidity status of Finnish lakes (Forsius et al., 2003). ANC is the standard indicator used in acidification studies and the most widely used chemical criterion in critical load calculations for surface waters (Henriksen et $a l ., 1995)$. Base saturation is a key indicator for the chemical conditions in the soil.

The $\mathrm{SO}_{4}$ concentrations in the lakes mimic the development of the $\mathrm{S}$ deposition with peak values during the 1980 s, followed by a sharp reduction to present day values (Fig. 2). A slower decline is expected in the future. The median change in $\mathrm{SO}_{4}$ concentrations between 2000 and 2030 is $-37 \%$. The difference in the $\mathrm{SO}_{4}$ concentrations between the lakes reflects the decreasing $\mathrm{S}$ deposition gradient towards the north. As expected, the largest changes in ANC are predicted to occur in the lakes with the lowest ANC values (Fig. 6) indicating the greatest sensitivity to acidic inputs. This is consistent with model results from acidsensitive sites in the UK (Jenkins and Cullen, 2001). The observed median water chemistry trend 1990-2001 of the 36 lakes was $-3.3 \mu \mathrm{eq} \mathrm{L} \mathrm{L}^{-1} \mathrm{yr}^{-1}$ for $\mathrm{SO}_{4}$ and $2.3 \mu \mathrm{eq} \mathrm{L} \mathrm{L}^{-1} \mathrm{yr}^{-1}$ for ANC. Modelled values for the same period are -5.7 and $0.52 \mu \mathrm{eq} \mathrm{L} \mathrm{L}^{-1} \mathrm{yr}^{-1}$, respectively (Fig. 6). The general trends are thus consistent, but the observed pace of the ANC recovery of the lakes is underestimated for the calibration period with the SMART model. This could lead to overly pessimistic scenarios of future surface water recovery.

Regional-scale analysis of long-term European and NorthAmerican surface water data has shown that the general 

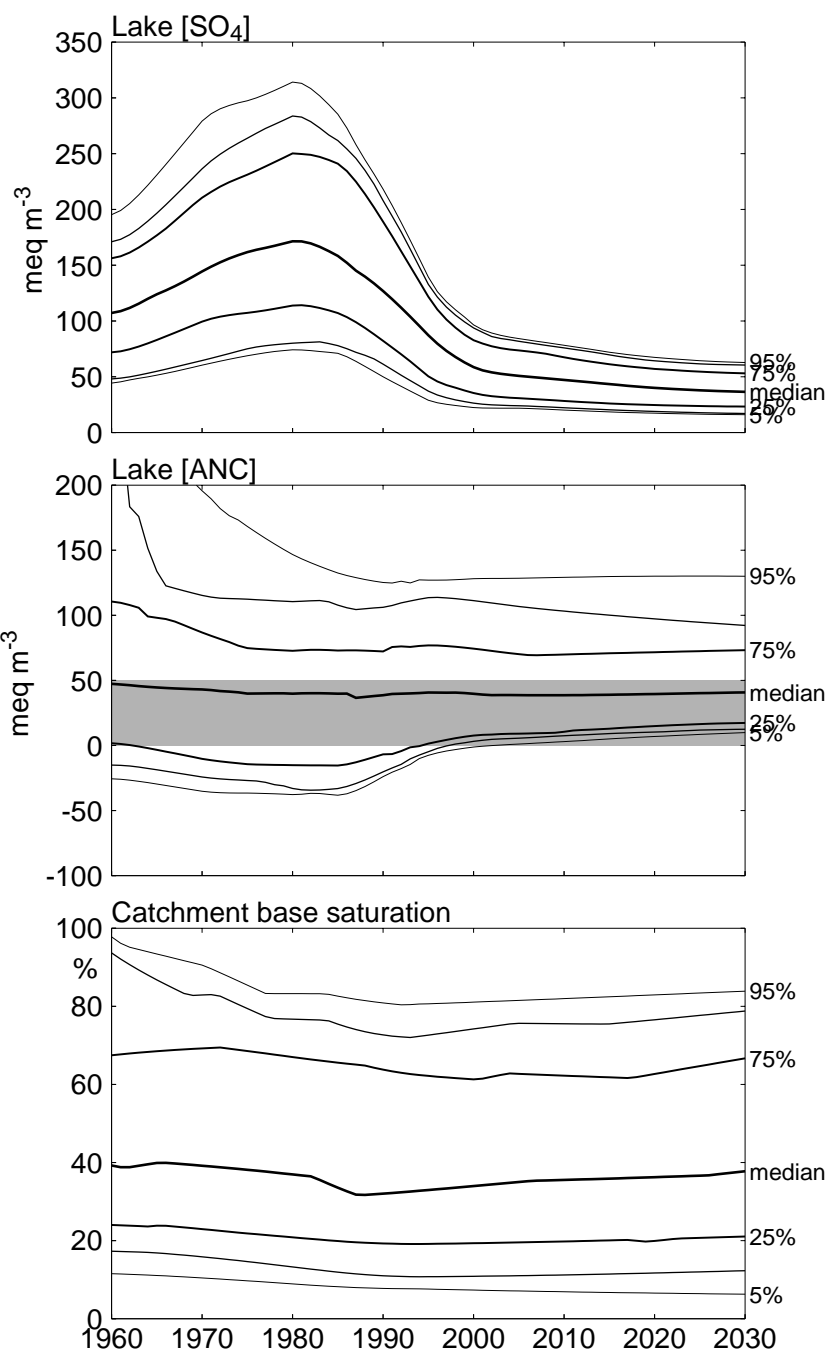

Fig. 6. Temporal development (1960-2030) of the percentiles (5, 10, $25,50,75,90$ and $95 \%)$ of annual lake water $\mathrm{SO}_{4}$ concentration and ANC as well as catchment soil base saturation of the 36 simulated lakes. The grey area between 0 and $50 \mathrm{~m}$ eq $L^{-1}$ of ANC marks the range used as chemical criterion to avoid damage to fish populations in the calculation of critical loads.

reduction in surface water acid anion concentrations (mainly sulphate) has led to increases in ANC, offset partly by decreases in base cations. This indicates that much of the improvement in the stream and lake water quality to date has been the result of decreasing ionic strength (Stoddard et al., 1999; Evans et al., 2001; Forsius et al., 2001). Since increases in ANC due to declining ionic strength can occur only while acid concentrations continue to fall (as a response to emission reductions), longer term surface water recovery must involve an increase in soil base saturation, with base cations replacing the acid cations $\left(\mathrm{H}^{+}\right.$and inorganic $\left.\mathrm{Al}\right)$ on exchange sites in the soil (Likens et al., 1996; Evans et al., 2001). However, such a base saturation increase is neither required nor implied by the surface water trends observed. If present or future acid deposition continues to outstrip base cation supply, soil base saturation may continue to fall at some sites (Likens et al., 1996; Evans et al., 2001). Complex processes such as mineralisation of organically bound $\mathrm{S}$ from catchment soils (Moldan et al., 2001) and interactions between climate-induced changes and acidification processes (Wright, 1998) are mechanisms which also might cause a lag in the run-off response.

The model results indicate that there has been a slight decrease in the base saturation at the lake catchments with present day base saturation values lowest but this decrease will stop if the current emission reduction plans are implemented (Fig. 6). For most lakes the modelled changes in base saturation are slow and thus remain small. No longterm soil data are available from the lake catchments to confirm this observation. There is, however, no evidence of any major regional-scale soil acidification in Finland (Tamminen and Starr, 1990); observed levels of soil acidification at four intensively studied Integrated Monitoring sites were not clearly related to acid deposition but were associated with soil organic matter contents (Starr and Ukonmaanaho, 2001).

It can, thus, be concluded that the largest reductions in acidic loading to Finnish lakes apparently have occurred already. Expected future reductions in emissions are likely to stop the soil acidification process at the most sensitive sites. Surface water chemistry will continue to recover at these sites but more slowly than during previous decades. The simulations for all 36 lakes show that ANC will be above zero by the year 2030. ANC values between 0 and $50 \mu \mathrm{eq}$ $\mathrm{L}^{-1}$ have been used as a chemical criterion in the calculations of critical loads for surface waters (Henriksen et al., 1995). Both detailed mass balance calculations at intensively studied sites as well as continued regional-scale monitoring are needed to confirm these findings.

\section{Concluding remarks}

The model simulations in this and several previous studies demonstrate that soils and surface waters respond in a dynamic way to changes in depositions of sulphur and nitrogen. This means that the time needed to achieve a selected environmental target depends on the eventual reductions in the emissions affecting the region. Regional model calibrations, like the present study using the SMART model, can be efficient tools for assessing such dynamic relationships between driving forces and the environmental targets. Due to the relatively fast response times, headwater lakes are particularly suited for such studies.

Uncertainties will always be associated with the 
application of model systems such as the one used here. These can be grouped roughly into two categories: (a) uncertainties due the model structure (conceptualisation), and (b) uncertainties in the model parameters and input data. With respect to structural uncertainties, many of the chemical process descriptions used in SMART (and similar models) have been called into question (see, e.g. Neal, 1997). In addition, the SMART model cannot deal explicitly with the spatial heterogeneity of a catchment; it works with catchment averages. To minimise the impact of this heterogeneity, only small headwater catchments are considered in this study. Also, since only some of the observations have been used in calibrating the model, there is an opportunity to use the remaining observations for model validation or, since validation in a strict sense is not possible, for model invalidation (Beven, 1993). It is, nowadays, common for decision makers to discuss uncertainties and to request their quantification for presented model results; unfortunately it is far less common to specify which indicator or type of uncertainty they mean, or to provide the resources necessary to carry out such uncertainty analyses.

The data set used in this study includes several years of observed lake water chemistry as well as fairly detailed soil chemistry measurements at each site. This improves the capability to make reliable regional-scale predictions and produce policy-relevant results, especially when looking, not so much at absolute values, but at general trends and relative changes.

The model predictions presented in this paper show that the recovery of surface water chemistry at the sites studied will continue but more slowly than during the previous decade. All the lakes have a modelled ANC above zero by the year 2030 (and most before that). There remains a slight discrepancy between the modelled and observed water chemistry trends of the lakes for the calibration period but the overall predicted patterns for the lakes are still assumed to be realistic. However, more work is needed to reduce the above-mentioned uncertainties.

\section{Acknowledgements}

This study was initiated during the DYNAMO project (ENV4-CT95-0030) of the Commission of European Communities. Results of the REPRO project of the Academy of Finland (project 50598) have also been used. The participants in the RECOVER:2010 (EVKI-CT-199900018) project are acknowledged for discussions and support.

\section{References}

Alveteg, M., Sverdrup, H. and Warfvinge, P., 1995. Regional assessment of the temporal trends in soil acidification in southern Sweden, using the SAFE model. Water Air Soil Pollut., 85, 2509-2514.

Baker, L.A. and Brezonik, P.L., 1988. Dynamic model of in-lake alkalinity generation. Water Resour. Res., 24, 65-74.

Beven, K., 1993. Prophecy, reality and uncertainty in distributed hydrological modelling. Advan. Water Resour., 16, 41-51.

Bull, K.R., Achermann, B., Bashkin, V., Chrast, R., Fenech, G., Forsius, M., Gregor, H.-D., Guardans, R., Haußmann, T., Hayes, F., Hettelingh, J.-P., Johannessen, T., Krzyzanowski, M., Kucera, V., Kvaeven, B., Lorenz, M., Lundin, L., Mills, G., Posch, M., Skjelkvåle, B.L. and Ulstein, J.M., 2001. Coordinated effects monitoring and modelling for developing and supporting international air pollution control agreements. Water Air Soil Pollut., 130, 119-130.

Cosby, B.J., Hornberger, G.M., Galloway, J.N. and Wright, R.F., 1985. Modeling the effects of acid deposition: Assessment of a lumped parameter model of soil water and streamwater chemistry. Water Resour. Res., 21, 51-63.

Cosby, B.J., Ferrier, R.C., Jenkins, A. and Wright, R.F., 2001. Modelling the effects of acid deposition: refinements, adjustments and inclusion of nitrogen dynamics in the MAGIC model. Hydrol. Earth Syst. Sci., 5, 499-517.

De Vries, W., Posch, M. and Kämäri, J., 1989. Simulation of the long-term soil response to acid deposition in various buffer ranges. Water Air Soil Pollut., 48, 349-390.

De Vries, W., Reinds, G.J., Posch, M. and Kämäri, J., 1994. Simulation of soil response to acidic deposition scenarios in Europe. Water Air Soil Pollut., 78, 215-246.

Dillon, P.J. and Molot, L.A., 1990. The role of ammonium and nitrate in the acidification of lakes and forested catchments. Biogeochemistry, 11, 23-43.

EMEP/MSC-W, 1998. Transboundary acidifying air pollution in Europe, Part 1: Calculation of acidifying and eutrophying compounds and comparison with observations. EMEP/MSCW Report 1/1998. Norwegian Meteorological Institute, Oslo, Norway. 150pp.

Evans, C.D., Cullen, J.M., Alewell, C., Kopacek, J., Marchetto, A., Moldan, F., Prechtel, A., Rogara, M., Vesely, J. and Wright, R.F., 2001. Recovery from acidification in European surface waters. Hydrol. Earth Syst. Sci., 5, 283-298.

Forsius, M., Kleemola, S., Vuorenmaa, J. and Syri, S., 2001. Fluxes and trends of nitrogen and sulphur compounds at Integrated Monitoring sites in Europe. Water Air Soil Pollut., 130, 16411648.

Forsius, M., Vuorenmaa, J., Mannio, J. and Syri, S., 2003. Recovery from acidification of Finnish lakes: Regional patterns and relations to emission reduction policy. Sci. Total Environ., 310, 121-132.

Henriksen, A., Posch, M., Hultberg, H. and Lien, L., 1995. Critical loads of acidity for surface waters - Can the $\mathrm{ANC}_{1 \text { imit }}$ be considered variable? Water Air Soil Pollut., 85, 2419-2424.

Järvinen, O. and Vänni, T., 1990. Bulk deposition chemistry in Finland. In: Acidification in Finland, P. Kauppi, P. Anttila and K. Kenttämies, (Eds.), Springer, Berlin, Germany. 151-165.

Jenkins, A. and Cullen, J.M., 2001. An assessment of the potential impact of the Gothenburg Protocol on surface water chemistry using the dynamic MAGIC model at acid sensitive sites in the UK. Hydrol. Earth Syst. Sci., 5, 529-541.

Johansson, M. and Janssen, P., 1994. Uncertainty analysis on critical loads for forest soils. In: Predictability and nonlinear modelling in natural sciences and economics, J.Grasman and G. Van Straten, (Eds.) Kluwer, Dordrecht, The Netherlands. 447-459. 
Johansson, M. and Tarvainen, T., 1997. Estimation of weathering rates for critical load calculations in Finland. Environ. Geol., 29, 158-164.

Johansson, M., Kämäri J., Pipatti, R., Savolainen, I., Tuovinen, J.-P. and Tähtinen, M., 1990. Development of an integrated model for the assessment of acidification in Finland. In: Acidification in Finland, P. Kauppi, P. Anttila and K. Kenttämies, (Eds.). Springer, Berlin, Germany. 1171-1193.

Kämäri, J., Posch, M., Kähkönen, A.-M. and Johansson, M., 1995. Modeling potential long-term responses of a small catchment in Lapland to changes in sulfur deposition. Sci. Total Environ., 160/161, 687-701.

Kuusela, K., 1977. Increment and timber assortment structure and their regionality of the forests of Finland in 1970-1976, Finnish Forest Research Institute, Helsinki, Finland, Folia Forestalia 320. 31pp. (In Finnish with English summary)

Leppäjärvi, R. (Ed.), 1987. Hydrological Yearbook 1981-1983. Publications of the Water Research Institute 66, Helsinki, Finland. 238pp.

Likens, G.E., Driscoll, C.T. and Buso, D.C., 1996. Long-term effects of acid rain: response and recovery of a forested ecosystem. Science, 272, 244-246.

Mälkönen, E., 1975. Annual primary production and nutrient cycle in some Scots pine stands. Helsinki, Finland, Communicationes Instituti Forestalis Fenniae 84. 87pp.

Mannio, J., 2001. Recovery pattern from acidification of headwater lakes in Finland. Water Air Soil Pollut., 130, 1427-1432.

Mannio, J., Räike, A. and Vuorenmaa, J., 2000. Finnish lake survey 1995: regional characteristics of lake chemistry. Internat. Verein Limnol., 27, 362-367.

Moldan, F., Wright, R.F., Löfgren, S., Forsius, M. and Skjelkvåle, B.L., 2001. Long-term changes in acidification and recovery at nine calibrated catchments in Norway, Sweden and Finland. Hydrol. Earth Syst. Sci. 5, 339-350.

Neal, C., 1997. A view of water quality from the Plynlimon watershed. Hydrol. Earth Syst. Sci., 1, 743-753.

Nuotio, T., Hyyppä, J. and Kämäri, J., 1985. Buffering properties of soils in 53 forested catchments in southern Finland. Aqua Fennica, 15, 35-40.

Nuotio, T., Hyyppä, J. and Nylander, J., 1990. Buffering capacity of Finnish soils and its dependence on geological factors in relation to the acidification sensitivity of lakes. In: Acidification in Finland, P. Kauppi, P. Anttila and K. Kenttämies, (Eds.). Springer, Berlin, Germany. 271-286.

Oliver, B.G., Thurman, E.M. and Malcolm, R.L., 1983. The contribution of humic substances to the acidity of colored natural waters. Geochim. Cosmochim. Acta, 47, 2031-2035.

Olsson, M. and Melkerud, P.-A., 1991. Determination of weathering rates based on geochemical properties of the soil. In: Environmental geochemistry in northern Europe, E. Pulkkinen, (Ed.) Geological Survey of Finland, Espoo, Finland, Special Paper 9, 69-78.

Olsson, M., Rosén, K. and Melkerud, P.-A., 1993. Regional modelling of base cation losses from Swedish forest soils due to whole-tree harvesting. Appl. Geochem., Special Issue 2, 189194.
Posch, M., Reinds, G.J. and De Vries, W., 1993. SMART - A Simulation Model for Acidification's Regional Trends: Model description and user manual. Mimeograph Series of the National Board of Waters and the Environment 477, Helsinki, Finland. 43pp.

Posch, M., Hettelingh, J.-P., Slootweg, J. and Downing, R.J. (Eds.), 2003. Modelling and mapping of critical thresholds in Europe. Status Report 2003, Coordination Center for Effects, RIVM Report 259101013, Bilthoven, Netherlands. iv+132pp.

Rask, M., Raitaniemi, J., Mannio, J., Vuorenmaa, J. and Nyberg, K., 1995. Losses and recoveries of fish populations in acidified lakes of southern Finland in the last decade. Water Air Soil Pollut., 85, 315-320.

Rask, M., Pöysä, H., Nummi, P. and Karppinen, C., 2001. Recovery of perch (Perca fluviatilis) in an acidified lake and subsequent responses in macroinvertebrates and the goldeneye (Bucephala clangula). Water Air Soil Pollut., 130, 1367-1372.

Rosén, K., 1982. Supply, loss and distribution of nutrients in three coniferous forest watersheds in central Sweden. Swedish University of Agricultural Sciences, Uppsala, Sweden, Reports in Forest Ecology and Forest Soils 41.

Schöpp, W., Posch, M., Mylona, S. and Johansson, M., 2003. Long-term development of acid deposition (1880-2030) in sensitive freshwater regions in Europe. Hydrol. Earth Syst. Sci. 7, 436-446.

Starr, M., Lindroos, A.-J., Tarvainen, T. and Tanskanen, H., 1998. Weathering rates in the Hietajärvi Integrated Monitoring catchment. Boreal Environ. Res., 3, 275-285.

Starr, M. and Ukonmaanaho, L., 2001. Results from the first round of the Integrated Monitoring soils programme. In: Forest condition monitoring in Finland. National Report 2000, . L. Ukonmaanaho and H. Raitio, (Eds.). The Finnish Forest Research Institute, Research Papers 824. 130-157.

Stoddard, J.L., Jeffries, D.S., Lükewille, A., Clair, T., Dillon, P.J., Driscoll, C.T., Forsius, M., Johannessen, M., Kahl, J.S., Kellogg, J.H., Kemp, A., Mannio, J., Monteith, D., Murdoch, P., Patrick, S., Rebsdorf, A., Skjelkvåle, B.L., Stainton, M.P., Traaen, T., Van Dam, H., Webster, K., Wieting, J. and Wilander, A., 1999. Regional trends in aquatic recovery from acidification in North America and Europe. Nature, 401, 575-578.

Syri, S., Johansson, M. and Kangas, L., 1998. Application of nitrogen transfer matrices for integrated assessment. Atmos. Environ., 32, 409-413.

Tamminen, P. and Starr, M., 1990. A survey of forest soil properties related to soil acidification in southern Finland. In: Acidification in Finland, P. Kauppi, P. Anttila and K. Kenttämies, (Eds.). Springer, Berlin, Germany. 237-252.

Vestreng, V. and Støren, E., 2000. Analysis of UNECE/EMEP Emission Data, MSC-W Status Report 2000. EMEP/MSC-W Note 1/00. Norwegian Meteorological Institute, Oslo, Norway.

Warfvinge, P., Falkengren-Grerup, U., Sverdrup, H. and Andersen, B., 1993. Modelling long-term cation supply in acidified forest stands. Environ. Pollut., 80, 209-221.

Wright, R.F., 1998. Effect of increased $\mathrm{CO}_{2}$ and temperature on runoff chemistry at a forested catchment in southern Norway (CLIMEX project). Ecosystems 1, 216-225. 